Atıf için / For Citation: F. Akdeniz, I. H. Sarpun, E. Tel, A. Aydin "Nucleon Densities of Copper Isotopes Calculated by Skyrme and Gogny Models", Süleyman Demirel Üniversitesi Fen Edebiyat Fakültesi Fen Dergisi, 16(1), 129-136, 2021.

\title{
Nucleon Densities of Copper Isotopes Calculated by Skyrme and Gogny Models
}

\author{
Ferhan AKDENIZ*1, İsmail Hakk1 SARPÜN², Eyyup TEL ${ }^{3}$, Abdullah AYDIN ${ }^{4}$

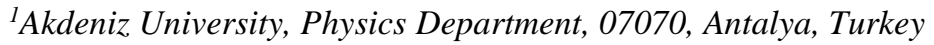 \\ ${ }^{2}$ Akdeniz University, Nuclear Sciences Application and Research Center, 07070, Antalya, Turkey \\ ${ }^{3}$ Osmaniye Korkut Ata University, Physics Department, 80000, Osmaniye, Turkey \\ ${ }^{4}$ Kırlkkale University, Physics Department, 71450, Kırlkkale, Turkey \\ *corresponding authore-mail: ferhanakdeniz@gmail.com
}

(Alinış / Received: 27.02.2021, Kabul / Accepted: 30.03.2021, Yayımlanma / Published: 27.05.2021)

\begin{abstract}
The ground state properties of the nuclei are generally calculated using two different methods, namely Skyrme and Gogny force methods. We have calculated nucleon densities of Copper isotopes by using Hartree-Fock-Skyrme (using Woods-Saxon Potential) (SHF-WS), Hartree-Fock-Skyrme (using Harmonic Oscillator Potential) (SHF-HO), Hartree-FockBogolyubov-Skyrme (HFB-S) and the Hartree-Fock-Bogolyubov-Gogny (HFB-G) methods. In the first two methods, the densities and rms (root mean square) radii for both proton and neutron of copper isotopes were calculated by different Skyrme parameters set. Theoretical calculated charge density was compared with experimental data of Angeli and Marinova to determine the best parameter set for each copper isotope. Then all evaluated nucleon densities via four different methods were compared each other. All methods gave similar results for all copper isotopes.
\end{abstract}

Key words: Hartree-Fock, Skyrme, Gogny, Nucleon Density

\section{Skyrme ve Gogny Modelleriyle Bakır İzotoplarının Yoğunluk Hesabı}

Özet: Çekirdeklerin taban durum özellikleri genellikle Skyrme ve Gogny kuvvet yöntemleri olmak üzere iki farklı yöntem kullanılarak hesaplanır. Hartree-Fock-Skyrme (Woods-Saxon Potansiyelini kullanarak) (SHF-WS), Hartree-Fock-Skyrme (Harmonik Osilatör Potansiyelini kullanarak) (SHF-HO), Hartree-Fock-Bogolyubov-Skyrme (HFB-S) ve Hartree-FockBogolyubov-Gogny (HFB-G) yöntemlerini kullanarak bakır izotoplarının nükleon yoğunluklarını hesapladık. İlk iki yöntemde, bakır izotoplarının hem proton hem de nötron yoğunlukları ve rms (karekök ortalama) yarıçapları, farklı Skyrme parametre seti ile hesaplandı. En iyi parametre setlerini belirlemek için her bir bakır izotopunun teorik olarak hesaplanan yük yoğunluğu Angeli ve Marinova deneysel verileriyle karşılaştırıldı. Sonra dört farklı yöntem ile elde edilen nükleon yoğunlukları birbiriyle karşılaştırılmıştır. Tüm yöntemler, tüm bakır izotopları için benzer sonuçlar verdi.

Anahtar kelimeler: Hartree-Fock, Skyrme, Gogny, Nükleon Yoğunluğu 


\section{Introduction}

The Hartree-Fock (HF) codes [1-3] are useful tools to describe the ground states properties of the spherical nucleus. Spherical HF codes have been used for 12 years and are developed by deriving gradient iterations [4-7]. In HF approach, equations are solved using an iteration, namely, harmonic oscillator or Wood-Saxon [8] wave functions which are recommended as wave function. The density $\rho(0)$ is generated based on these wave functions. Then, the iterations are made between the intensity and $\mathrm{U}(\rho)$ energy potential for $\varphi$ wave function.

The Skyrme force [9-10] is the effective force for HF calculations. In this way, quantities, such as core radii, density distributions and surface thickness, which are very important and can be measured experimentally, can be calculated. HF codes are applied to the specified Skyrme force by fitting the least squares method. It is also fitted to ground states correlations [11] and nucleus excitation studies.

The properties of a nucleus which comprises neutrons and protons are determined by the forces which acting between the nucleons. The two-body and three-body interactions potentials can be written as;

$$
\begin{gathered}
\vec{V}(i, j)=t_{0}\left(1+x_{0} P_{x}\right) \delta\left(\vec{r}_{i}-\vec{r}_{j}\right)+\frac{1}{2} t_{1}\left(1+x_{1} P_{x}\right)\left[\vec{P}_{12}^{\prime}{ }^{2} \delta\left(\vec{r}_{i}-\vec{r}_{j}\right)+\delta\left(\vec{r}_{i}-\vec{r}_{j}\right) \vec{P}_{12}^{2}\right] \\
+t_{2}\left(1+x_{2} P_{x}\right) \vec{P}_{12}^{\prime} \delta\left(\vec{r}_{i}-\vec{r}_{j}\right) \vec{P}_{12}+i t_{4} \vec{P}_{12}^{\prime} \cdot \delta\left(\vec{r}_{i}-\vec{r}_{j}\right)\left(\sigma_{i}+\sigma_{j}\right) \times \vec{P}_{12} \\
\vec{V}(i, j, k)=\frac{1}{6} t_{3}\left(1+x_{3} P_{x}\right) \rho\left(\frac{\vec{r}_{i}+\vec{r}_{j}}{2}\right) \delta\left(\vec{r}_{i}-\vec{r}_{j}\right)
\end{gathered}
$$

to calculate Skyrme interaction potential;

$$
V_{\text {Skyrme }}=\sum_{i<j} \vec{V}_{i j}+\sum_{i<j<k} \vec{V}_{i j k}
$$

In these equations, $\delta$ is delta function, $\vec{p}_{12}=\mp i\left(\vec{\nabla}_{1}-\vec{\nabla}_{2}\right)$ is relative momentum operator acting on the wave functions moving to the right or left, $\mathrm{P}_{\mathrm{x}}$ is spin exchange operator and $\sigma$ is Pauli spin matrices. The interaction of two objects depends on seven parameters $\left(t_{0}, t_{1}, t_{2}, x_{0}, x_{1}, x_{2}\right.$ and $\left.t_{4}\right)$, while nine parameters (also, $x_{3}$ and $\left.t_{3}\right)$ are involved in for three-body.

The zero-range three-body force in the original Skyrme force is assumed to be equivalent to two-body dependent interaction.

$$
\vec{V}(i, j) \cong \vec{V}(i, j, k)
$$


For effective interactive HF calculations, the Skyrme interactive HF(SHF) method is the best suited for ground state calculations of all nuclei. The SHF method is essentially based on the shell model, which assumes that one nucleon moves independently within an average central potential of other nucleons.

Depending on single particle states three local density functions are:

$$
\begin{gathered}
\rho_{q}(\vec{r})=\sum_{i, \sigma} w_{i}\left|\varphi_{i}(\vec{r}, \sigma, q)\right|^{2} \\
\tau_{q}(\vec{r})=\sum_{i, \sigma} w_{i}\left|\vec{\nabla} \varphi_{i}(\vec{r}, \sigma, q)\right|^{2} \\
\vec{J}_{q}(\vec{r})=(-i) \sum_{i, \sigma, \sigma^{\prime}} w_{i} \varphi_{i}^{*}(\vec{r}, \sigma, q)\left[\vec{\nabla} \varphi_{i}\left(\vec{r}, \sigma^{\prime}, q\right) \times\left\langle\sigma|\vec{\sigma}| \sigma^{\prime}\right\rangle\right]
\end{gathered}
$$

Here, $\rho_{\mathrm{q}}$ is proton density, $\tau_{\mathrm{q}}$ is kinetic energy, $\overrightarrow{\mathrm{J}}_{\mathrm{q}}$ is spin - orbital density (wherein $\mathrm{q}=$ $\mathrm{n}$ and $\mathrm{p}$, represent protons and neutrons). Also, $\mathrm{w}_{\mathrm{i}}$ denotes the occupation probability of the states $i$ and $\sigma$ is Pauli spin matrice. The SHF method is a self-compatible field method.

The most important advantage of Skyrme interaction is that HF energy is expressed by three density functions:

$$
\begin{gathered}
E_{H F}=\int H\left(\rho_{q}, \tau_{q}, \vec{J}_{q}\right) d^{3} r \\
E_{H F}=E_{\text {Skyrme }}+E_{\text {Coulomb }}+E_{\text {pair }}-E_{c m}
\end{gathered}
$$

where $E_{\text {Skyrme }}$ is energy function of Skyrme force, $E_{\text {Coulomb }}$ is Coulomb interaction energy, $E_{\text {pair }}$ is the coupling interaction energy of nucleons and $E_{c m}$ is the correction term for the center of mass of the mean field [5].

Skyrme type forces are widely used phenomenological forces. With the development of the Skyrme force and the identification of new parameter sets, it is also applied to cores far from the spherical structure. Skyrme force parameters can be adjusted by comparison of experimental data with theoretical results or only by theoretical approaches.

Another phenomenological force is the Gogny force which is a finite-range two-body interaction [12-13]. The use of the Gogny interaction with the HF method yields a nonrelativistic approach like the SHF method.

Another type of HF method is the Hartree-Fock-Bogolyubov (HFB) method [14-15]. Independent particles moving within an average potential are depicted as single 
particles [16] Correlations between these particles and incomplete shells give the HFB theory. HFB-S and HFB-G methods [17] were developed by using Skyrme and Gogny forces.

\section{Material and Method}

The nucleon densities of ${ }^{63,65} \mathrm{Cu}$ isotopes were calculated by using HAFOMN [18] computer program for HO potential and HARTREE-FOCK [19] code for WS potential by HF method with Skyrme interaction. TALYS 1.95 nuclear reaction code [20] was used to calculate Skyrme and Gogny interactions by HFB method in the same manner.

HAFOMN code (HP) [18] uses the harmonic oscillator wave function (HODF) as a single particle wave function, while the HARTREE-FOCK program (H-FP) [20] uses the Woods Saxon wave function (WSDF). In this study, using a large number of parameter sets in HARTREE-FOCK and HAFOMN codes, the ground state properties of the nucleus are calculated.

TALYS 1.95 nuclear reaction code was used in the theoretical calculations of cross sections as well as in evaluation of nucleus structure parameters. Input file of the calculations basically should have projectile particle or nuclei, target element, target mass and incident energy parameters. The other parameters should added to input file according to the purpose of study [20].

Using SkA [21], GS6 [22], SKM* [23], SGII [24], Sly4, Sly5, SLy6, SLy7 [25], SLy8, SLy9 and SLy10 [26] parameter sets, proton and neutron densities were obtained for each. Theoretical calculated charge density was compared with experimental data of Angeli and Marinova [27] works to determine which is the best parameter set in the calculations for Skyrme and Gogny interactions. These are the parameters sets of Skyrme force which we used in the calculations are given in "Table 1".

Table 1. Used Skyrme parameter sets and coefficients. $t_{0}, t_{1}, t_{2}, t_{3}$ are in $\left(\mathrm{MeV} \mathrm{fm}^{3}\right)$, others have no unit [28].

\begin{tabular}{ccccccccccc}
\hline Parameters & $\mathbf{t}_{\mathbf{0}}$ & $\mathbf{t}_{\mathbf{1}}$ & $\mathbf{t}_{\mathbf{2}}$ & $\mathbf{t}_{\mathbf{3}}$ & $\mathbf{x}_{\mathbf{0}}$ & $\mathbf{x}_{\mathbf{1}}$ & $\mathbf{x}_{\mathbf{2}}$ & $\mathbf{x}_{\mathbf{3}}$ & $\mathbf{W}_{\mathbf{0}}$ & Alpha \\
\hline SkA & -1602.78 & 570.88 & -67.7 & 8000 & -0.02 & 0 & 0 & -0.28 & 125 & $1 / 3$ \\
GS6 & -1012 & 209 & -76.3 & 10619 & 0.139 & 0 & 0 & 1 & 105 & 1 \\
SkM* & -2645 & 410 & -135 & 15595 & 0.09 & 0 & 0 & 0 & 130 & $1 / 6$ \\
SGII & -2645 & 340 & -41.9 & 15595 & 0.09 & -0.0588 & 1.425 & 0.06044 & 105 & $1 / 6$ \\
SLy4 & -2488.913 & 486.818 & -546.395 & 13777 & 0.834 & -0.3438 & -1 & 1.354 & 123 & $1 / 6$ \\
SLy5 & -2483.45 & 484.23 & -556.69 & 13757 & 0.776 & -0.317 & -1 & 1.263 & 125 & $1 / 6$ \\
SLy6 & -2479.5 & 462.18 & -448.61 & 13673 & 0.825 & -0.465 & -1 & 1.355 & 122 & $1 / 6$ \\
SLy7 & -2480.8 & 461.29 & -433.93 & 13669 & 0.848 & -0.492 & -1 & 1.393 & 126 & $1 / 6$ \\
SLy8 & -2481.41 & 480.78 & -538.34 & 13731 & 0.8024 & -0.3424 & -1 & 1.3061 & 122.425 & $1 / 6$ \\
SLy9 & -2511.13 & 510.6 & -429.8 & 13716 & 0.7998 & -0.6213 & -1 & 1.3727 & 119 & $1 / 6$ \\
SLy10 & -2506.77 & 430.98 & -304.95 & 13826.41 & 1.0398 & -0.6745 & -1 & 1.6833 & 90.685 & $1 / 6$
\end{tabular}

\section{Conclusion and Comment}

The calculated charge radius of nucleus was compared with experimental data of Angeli and Marinova [27], then best compatible set of Skyrme parameters were determined for 
Skyrme interaction using WS with HO. These are SLy4 for ${ }^{63} \mathrm{Cu}$ and SLy8 for ${ }^{65} \mathrm{Cu}$ using WS potential, SGII for ${ }^{63} \mathrm{Cu}$ and ${ }^{65} \mathrm{Cu}$ using $\mathrm{HO}$ given in "Table 2".

Table 2. Charge radius of ${ }^{63,65} \mathrm{Cu}$ isotopes were calculated by different parameter sets using WS and HO methods. Comparison of calculated charge radii with experimental values of [27].

\begin{tabular}{ccccc}
\hline $\mathbf{R}_{\text {charge }}$ & $\begin{array}{c}\mathbf{Z}=\mathbf{2 9} \mathbf{N = 3 4} \\
{ }^{\mathbf{6 3}} \mathbf{C u}\end{array}$ & $\begin{array}{c}\mathbf{Z}=\mathbf{2 9} \mathbf{N}=\mathbf{3 6} \\
{ }^{\mathbf{6 5}} \mathbf{C u}\end{array}$ & $\begin{array}{c}\mathbf{Z}=\mathbf{2 9} \mathbf{N}=\mathbf{3 4} \\
{ }^{\mathbf{6}} \mathbf{C u}\end{array}$ & $\begin{array}{c}\mathbf{Z}=\mathbf{2 9} \mathbf{N}=\mathbf{3 6} \\
{ }^{\mathbf{6 5}} \mathbf{C u}\end{array}$ \\
\hline Experim. [27] & $\mathbf{3 . 8 8 2 3}$ & $\mathbf{3 . 9 0 2 2}$ & $\mathbf{3 . 8 8 2 3}$ & $\mathbf{3 . 9 0 2 2}$ \\
SkA & 3.8867 & 3.9102 & 4.0081 & 4.0696 \\
GS6 & 3.4505 & 3.5745 & 3.5477 & 3.5750 \\
SkM* & 3.8678 & 3.8975 & 3.9013 & 3.9193 \\
SGII & 3.8527 & 3.8806 & $\mathbf{3 . 8 9 2 1}$ & $\mathbf{3 . 9 1 0 1}$ \\
SLy4 & $\mathbf{3 . 8 8 1 3}$ & 3.9088 & 3.9075 & 3.9270 \\
SLy5 & 3.8725 & 3.9004 & 3.8975 & 3.9173 \\
SLy6 & 3.8650 & 3.8928 & 3.8947 & 3.9144 \\
SLy7 & 3.8673 & 3.8926 & 3.8938 & 3.9140 \\
SLy8 & 3.8740 & $\mathbf{3 . 9 0 1 4}$ & 3.8999 & 3.9194 \\
SLy9 & 3.9307 & 3.9569 & 3.9685 & 3.9855 \\
SLy10 & 3.8842 & 3.9083 & 3.9240 & 3.9397 \\
\hline
\end{tabular}

Then neutron and proton density graphs versus nucleus radii were plotted according to the best Skyrme parameter set for SHF-WS and SHF-HO calculations. The theoretically calculated proton and neutron densities of ${ }^{63,65} \mathrm{Cu}$ isotopes by HAFOMN code were given in "Figs. 1 and 2", respectively. Neutron and proton densities have been evaluated theoretically using Gogny and Skyrme interactions in HFB model by TALYS nuclear reaction code and are given in "Figs. 1 and 2".

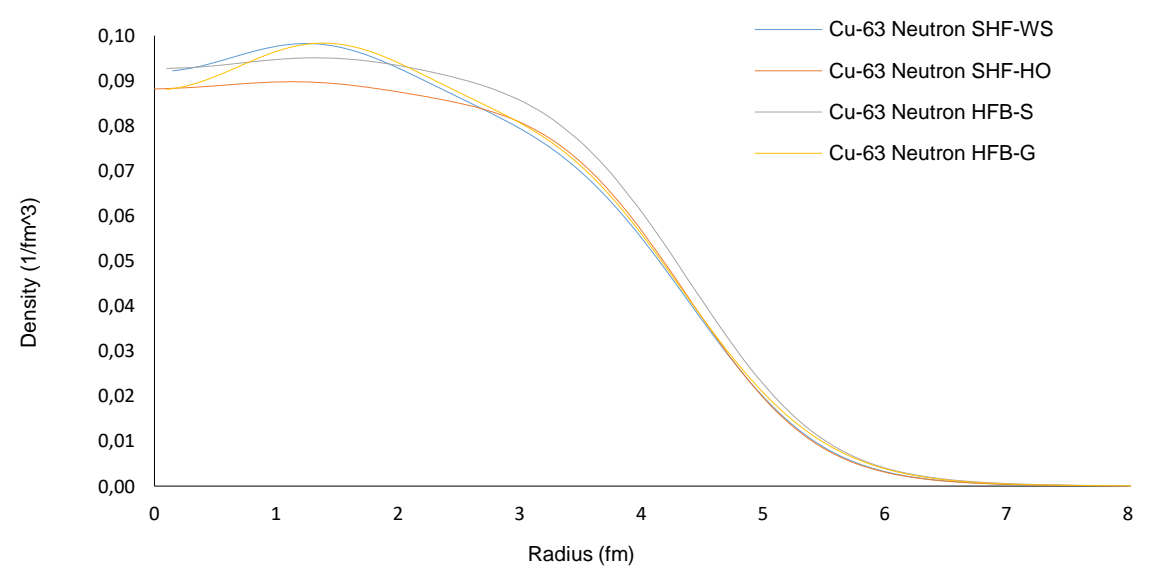




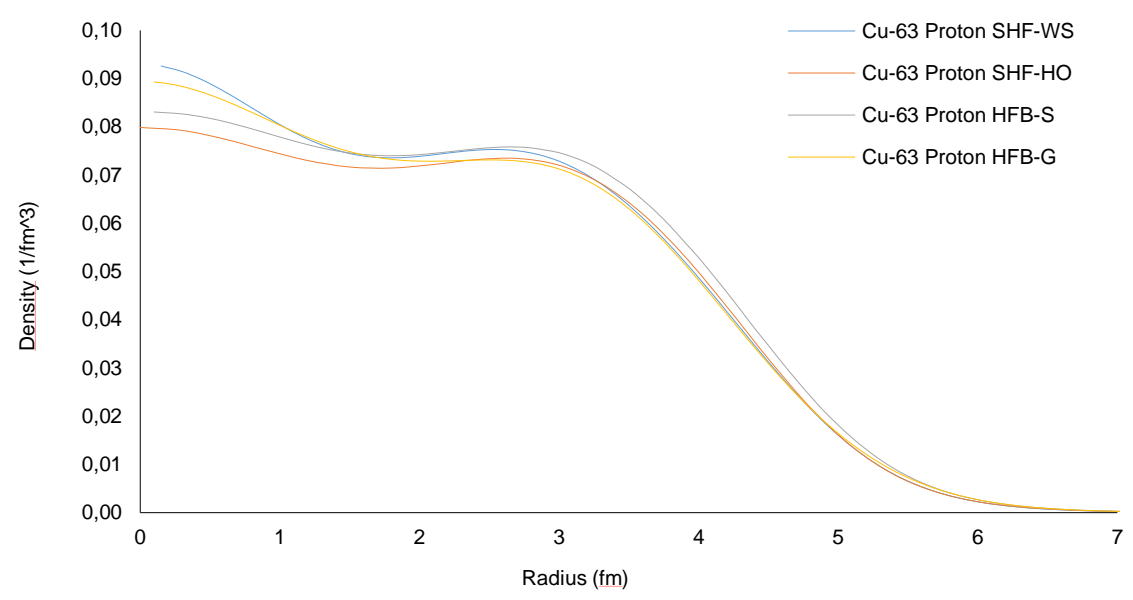

Figure 1. Neutron and Proton densities of ${ }^{63} \mathrm{Cu}$
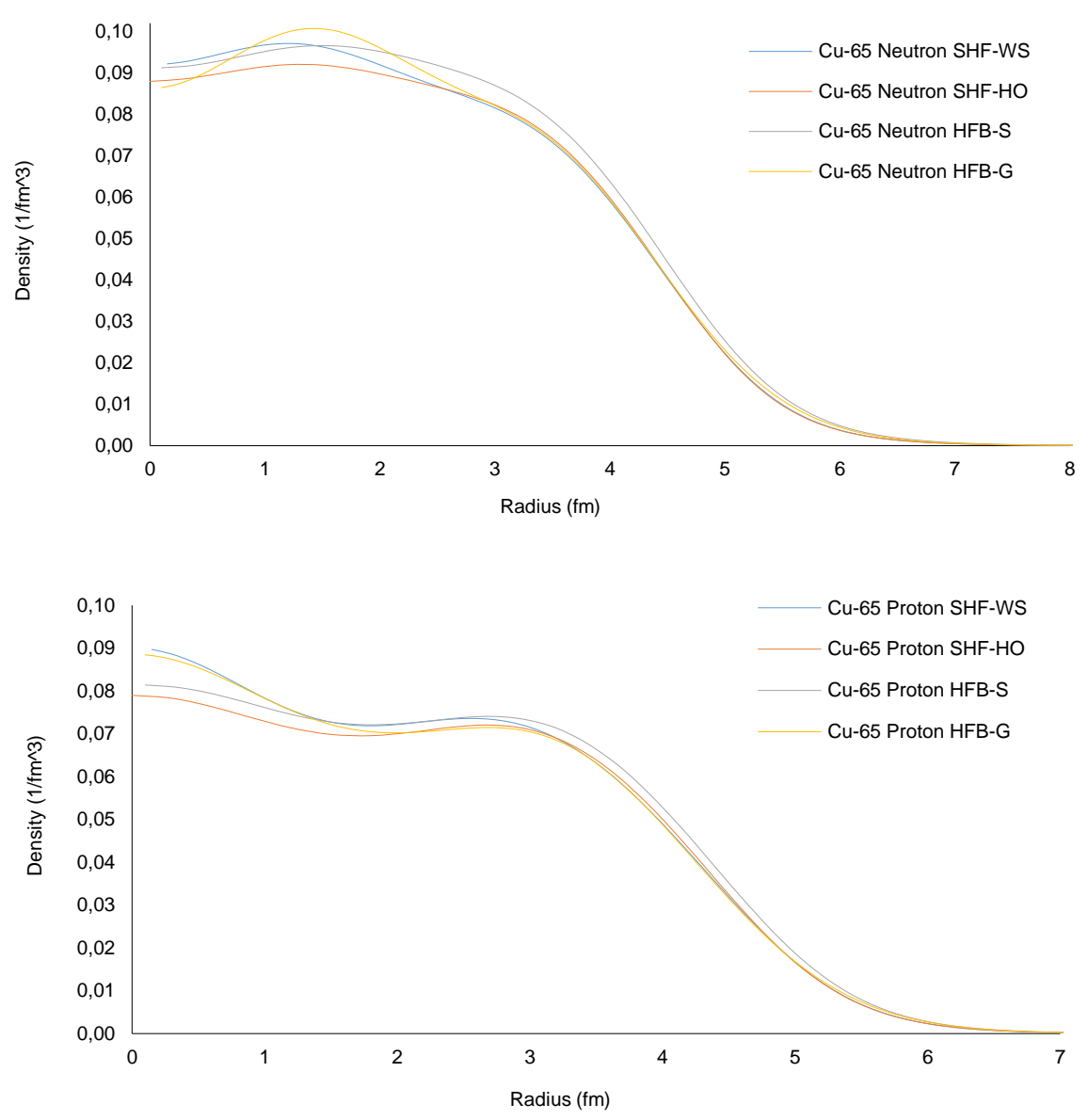

Figure 2. Neutron and Proton densities of ${ }^{65} \mathrm{Cu}$

\section{Author Statement}

Ferhan Akdeniz: Investigation, Visualization, Original Draft Writing, Formal Analysis,

İsmail Hakkı Sarpün: Investigation, Project Administration, Supervision, Review and Editing, Data Curation, Software

Eyyup Tel: Investigation, Advice, Resource/Material/Instrument Supply, Formal Analysis, Methodology Abdullah Aydın: Investigation, Observation, Investigation, Validation, Conceptualization 


\section{Acknowledgment}

As the authors of this study, we declare that we do not have any support and thank you statement.

\section{Conflict of Interest}

As the authors of this study, we declare that we do not have any conflict of interest statement.

\section{Ethics Committee Approval and Informed Consent}

As the authors of this study, we declare that we do not have any ethics committee approval and/or informed consent statement.

\section{References}

[1] D. R Hartree, "The wave mechanics of an atom with a non-Coulomb central field. part I. theory and methods," Proc. Camb. Phil. Soc., 24 (1), 89-110, 1928.

[2] V Fock, "Näherungsmethode zur lösung des quantenmechanischen Mehrkörperproblems," Z. Physik., 61 (1-2), 126-148, 1930.

[3] R. D. Adamson, "Novel methods for large molecules in quantum chemistry," Ph.D. Thesis, University of Cambridge, Cambridgeshire, England, 1998.

[4] H. Pfeiffer, P .G. Reinhard, and D. Drechsel, "A model study of Hartree-Fock and Linear Response in coordinate space,” Z. Phys. A, 292 (4), 375-383, 1979.

[5] P. G. Reinhard, and R. Y. Cusson, "A comparative study of Hartree-Fock iteration techniques," Nucl. Phys. A, 378 (3), 418-442, 1982.

[6] M. R. Strayer, R. Y. Cusson, A. S. Umar, P. G. Reinhard, D. A. Bromley, and W. Greiner, "Timedependent Hartree-Fock picture of nuclear molecular resonances," Phys. Lett. B, 135 (4), 261, 1984.

[7] P. G. Reinhard, F. Grümmer and K. Goeke, "Collective mass parameters and linear response techniques in three-dimensional grids," Z. Phys. A, 317 (3), 339-349, 1984.

[8] R. D. Woods and D. S. Saxon, "Diffuse Surface Optical Model for Nucleon-Nuclei Scattering," Phys. Rev., 95, 577, 1954.

[9] T. H. R. Skyrme, "The Nuclear Surface,", Phil. Mag., 1, 1043-1054, 1956.

[10] T. H. R. Skyrme, "The effective nuclear potential," Nucl. Phys., 9 (2), 615-634, 1959.

[11] P. G. Reinhard and J. Friedrich, "A sum-rule approach to nuclear ground state correlations," Z. Phys. 321, 619, 1985.

[12] D. Gogny, "Simple separable expansions for calculating matrix elements of two- body local interactions with harmonic oscillator functions," Nucl. Phys. A, 237(3), 399-418, 1975.

[13] J. R. Stone and P. G. Reinhard, "The Skyrme interaction in finite nuclei and nuclear matter," Prog. Part. Nucl. Phys., 58, 587-657, 2007.

[14] N. N. Bogolyubov, "On a Variational Principle in the Many Body Problem," Sov. Phys. Dokl., 3, 292-294, 1985.

[15] V.G. Soloviev, Theory of complex nuclei. Pergamon Press, Oxford, 455 p., 1976.

[16] P. Ring and P. Schuck, The nuclear many body problems, Springer, Berlin, Heidelberg, 715 p., 1980.

[17] J. Déchargé and D. Gogny, "Hartree-Fock-Bogoliubov calculations with the D1effective interaction on spherical nuclei," Phys. Rev. C, 21 (4), 1568-1593, 1980.

[18] http://phys.lsu.edu/graceland/faculty/cjohnson/skhafo.f, Louisiana State University, 28 Ocak 2007.

[19] P.G. Reinhard and H. Flocard, "Nuclear effective forces and isotope shifts," Nucl. Phys. A, 584 (3), 467-488, 1995.

[20] J. Koning, H. Hilaire, and S. Goriely, TALYS-1.95, NRG, Netherland, http://www.talys.eu (2017).

[21] H. S. Kohler, "Skyrme force and the mass formula," Nucl. Phys. A, 258 (2), 301-316, 1976.

[22] S. Krewald, V. Klemt, J. Speth and A. Faessler, "On the use of Skyrme forces in self-consistent RPA calculations," Nucl. Phys. A, 281 (2), 166-206, 1977.

[23] M. Brack, C. Guet and H. B. Hakansson, "Selfconsistent smiclassical description of average nuclear properties- a link between microscopic and macroscopic models," Phys. Rep., 123 (5), 275-364, 1986. 
[24] N. V. Gia and H. Sagawa, "Spin isospin and pairing properties of modified Skyrme interactions," Phys. Lett. B, 106, 379, 1981.

[25] E. Chabanat, P. Bonche, P. Haensel, J. Meyer, and R. Schaeffer, "A Skyrme parametrization from subnuclear to neutron star densities,” Nucl. Phys. A, 627, 710-746, 1997.

[26] E. Chabanat, P. Bonche, P. Haensel, J. Meyer, and R. Schaeffer, "A Skyrme parametrization from subnuclear to neutron star densities part II.," Nucl. Phys. A, 635, 231-256, 1998.

[27] I. Angel and K. P. Marinova, "Table of experimental nuclear ground state charge radii: An update," Atomic Data and Nuclear Data Tables, 99 (1), 69-95, 2013.

[28] R. Baldık, "Skyrme etkileşmesi kullanılarak bazı egzotik çekirdeklerin taban durum özelliklerinin incelenmesi,” Ph.D. Thesis, Zonguldak Karaelmas University, 2010. 